\title{
AN ANALYSIS OF MICROSTRUCTURE AND MECHANICAL PROPERTIES ON FRICTION STIR WELDED JOINT OF DISSIMILAR 304 STAINLESS STEEL AND COMMERCIALLY PURE ALUMINIUM
}

\begin{abstract}
In this study, friction stir welding of dissimilar 304 stainless steel and commercially pure aluminium was performed under the following condition of tool rotational speed $1000 \mathrm{rpm}$, traverse speed $60 \mathrm{~mm} / \mathrm{min}$ and tool tilt angle 2 degree. Microstructural characterisation was carried out by optical microscope, scanning electron microscope (SEM). Optical images shows that the microstructural change is very minimum in steel side when compared to aluminium side due to the difference in mechanical and thermal properties. The intermetallic compound $\mathrm{Al}_{3} \mathrm{Fe}$ was observed at the interfacial region and stir region of the welded joint. The maximum ultimate tensile strength is $78 \%$ of commercially pure aluminium base metal. Microhardness profile was measured across the weld interface and the maximum value reaches at the stir zone due to the formation of intermettalics.

Keywords: Friction stir welding, dissimilar materials, microstructure, mechanical properties, weld nugget
\end{abstract}

\section{Introduction}

Aluminium has good heat transfer property, good formability and less weight which are vital in aerospace industries, automobile parts, some of the navel parts etc. Stainless steel has high strength, high corrosion resistance and high toughness. Stainless steel is a significant structural material which is mainly used in automobiles and aerospace industry [1]. Joining of dissimilar metals is commonly more challenging than the joining of similar materials due to the difference in thermal and mechanical properties of the materials. In order to take full advantage of the properties of aluminium and steel it is significant to make high quality joints [2]. Joining of aluminium and stainless steel solve many industrial problems like nuclear reactor components to domestic cooking utensils. In the field of cryogenics, the cryogenic liquid is stored in Al chambers and transferred through SS pipeline $[1,3,4]$.Nuclear industry also looking forward for the Stainless steel and aluminium assembly to fabricate neutron sensitive ion chambers. Joining of aluminium and stainless steel helps to solve the problem for developing industrial products especially in automobile industry due to the increase in strength-to-weight ratio and fuel efficiency $[5,6]$. The joints has the application in the field of cryogenics, nuclear, structural industries and domestic appliances. Friction stir welding, (FSW) developed by The Welding Institute (TWI) in 1991, is a solid-state welding process. Friction stir welding is a non-consumable tool attached with a desired designed pin is inserted to butting edge of the plates to be joined. Tool shoulder should touch the plate surface. Under this condition the tool is rotated and traversed along the bond line. Frictional heat is generated, material gets softened locally and plastic deformation of the work piece occurs. Tool rotation and translation expedite material flow from front to back of the pin and welded joint is produced. Friction stir welding has many advantages like low energy distortion, short weld time and relatively low welding temperature when compared to fusion welding. Moreover friction stir welding is commonly used to join dissimilar materials [7].

Ghosh et al reported that the joining of 6061 aluminium alloy and 304 stainless steel. The result shows the peak microhardness and ultimate tensile strength were found to be maximum at the tool rotational speed of $710 \mathrm{rpm}$, where $\mathrm{Fe}_{3} \mathrm{Al}$ and $\mathrm{FeAl}_{2}$ appeared along with $\mathrm{Fe}_{2} \mathrm{Al}_{5}$ [8]. Habibnia et al reported the joining of 5050 aluminium (Al) alloy and 304 stainless welding. To improve the welding quality, the heat generation should be reduced. Therefore, a decrease in the tool rotational speed and increase in the tool feed rate need to be maintained and the defect on the stir zone was reduced by increasing the tool offset up to $1.5 \mathrm{~mm}$ [9]. Lee et al reported the joining of Al 6056 and 304 stainless steel where the intermetallic compound was identified as $\mathrm{Al}_{4} \mathrm{Fe}$ using transmission electron microscopy [10]. Uzun et al reported the joining of 6013-T4 Al and X5CrNi18-10 stainless steel. They discussed the microstructure at different regions, microhardness, fatigue property, and diffusion between the chemical particles. The objective of the present work is to examine the microstructure and mechanical properties of the friction stir welded joint for 304 stainless steel and commercially pure aluminium.

\footnotetext{
* DEPARTMENT OF METALLURGY AND MATERIALS ENGINEERING, INDIAN INSTITUTE OF ENGINEERING SCIENCE AND TECHNOLOGY, SHIBPUR, HOWRAH-711103, INDIA 


\section{Experimental procedure}

Friction stir welding between 304 stainless steel and commercially pure aluminium were done. In friction stir welding machine, 304 stainless steel was placed in advancing side and commercially pure aluminium was placed in retreating side. The dimensions of the plates are $160 \mathrm{~mm}$ length $\times 60 \mathrm{~mm}$ width $\times 3 \mathrm{~mm}$ thickness. The chemical composition of commercially pure aluminium is Al-0.02Fe-0.2Si-0.003Mn-0.002S-0.002P-0.005N (wt \%) and the $304 \mathrm{SS}$ is Fe- $18.2 \mathrm{Cr}-8.4 \mathrm{Ni}-1.34 \mathrm{Mn}-0.04 \mathrm{C}-0.4 \mathrm{Si}$ (wt $\%$ ). The mechanical properties of base materials were shown in Table 1. A tungsten carbide tool with a shoulder diameter of $25 \mathrm{~mm}$ and a conical probe of diameter $6 \mathrm{~mm}$ and pin length of $2.7 \mathrm{~mm}$ were used for the welding process. Friction stir welding was performed using tool rotational speed of $1000 \mathrm{rpm}$, traverse speed of $60 \mathrm{~mm} / \mathrm{min}$ and the tool tilt angle of $2^{\circ}$. During the welding process, the welding tool was plunged in the aluminium side with the offset of $1.25 \mathrm{~mm}$ from the interface. The offset was made to avoid the tool breakage and pin erosion. The microstructures were observed in the optical microscope and the weld nugget was characterize in scanning electron microscope (SEM). The chemical analysis of the welded joints was done with help of SEM (EDS) energy dispersive spectroscopy. Fracture surfaces were examined in Scanning Electron Microscope (SEM) and the intermetallic phases were analysed using X-Ray Diffraction (XRD). The mechanical properties of the welded samples were carried with help of microhardness and tensile test.

TABLE 1

Mechanical properties of base materials at room temperature

\begin{tabular}{|c|c|c|c|}
\hline \hline Alloys & $\begin{array}{c}\text { 0.2\% Proof stress } \\
\text { (MPa) }\end{array}$ & $\begin{array}{c}\text { Ultimate tensile } \\
\text { strength (MPa) }\end{array}$ & $\begin{array}{c}\text { Elongation at } \\
\text { Fracture (\%) }\end{array}$ \\
\hline CP Al & 106 & 132.1 & 9.8 \\
\hline SS 304 & 265 & 628 & 55 \\
\hline
\end{tabular}

\section{Results and discussion}

\subsection{Microstructural characterization}

The optical microstructure of friction stir welded sample were shown in Fig. 1. In friction stir welded joints the microstructures consists of four distinct zones - (a) base metal (BM), (b) heat affected zone (HAZ), (c) thermo mechanically affected zone (TMAZ) and (d) stir zone (SZ). The microstructural changes in stainless steel very minimum due to the mechanical and thermal properties of the material as compared to aluminium. So, the microstructure in the HAZ region does not show enough changes when compared to the base material. The grains are finer in the stir zone due to the rotation of the pin and near the weld interface. Steel particles were observed in the aluminium side due to the stirring action of the pin, which dragged small bits of steel from the surface and distributed over the aluminium side. The steel particles are in irregular shape. In aluminium side grains are even finer and equiaxed due to the severe plastic deforma- tion and recrystallization of the material. In TMAZ region, the grains are elongated due to the thermo-mechanical effect. In heat affected zone fully grown grain structure is observed.

The characterisation of the welded sample using Scanning electron microscope is shown in Fig. 2a shows the steel particles are uneven shape and unevenly distributed. In steel side the material flow was within the interface region. The interface has a non-linear shape. Lee et al explained that the non linear shape formed was due to outer edge of the pin stirred the steel side [10].
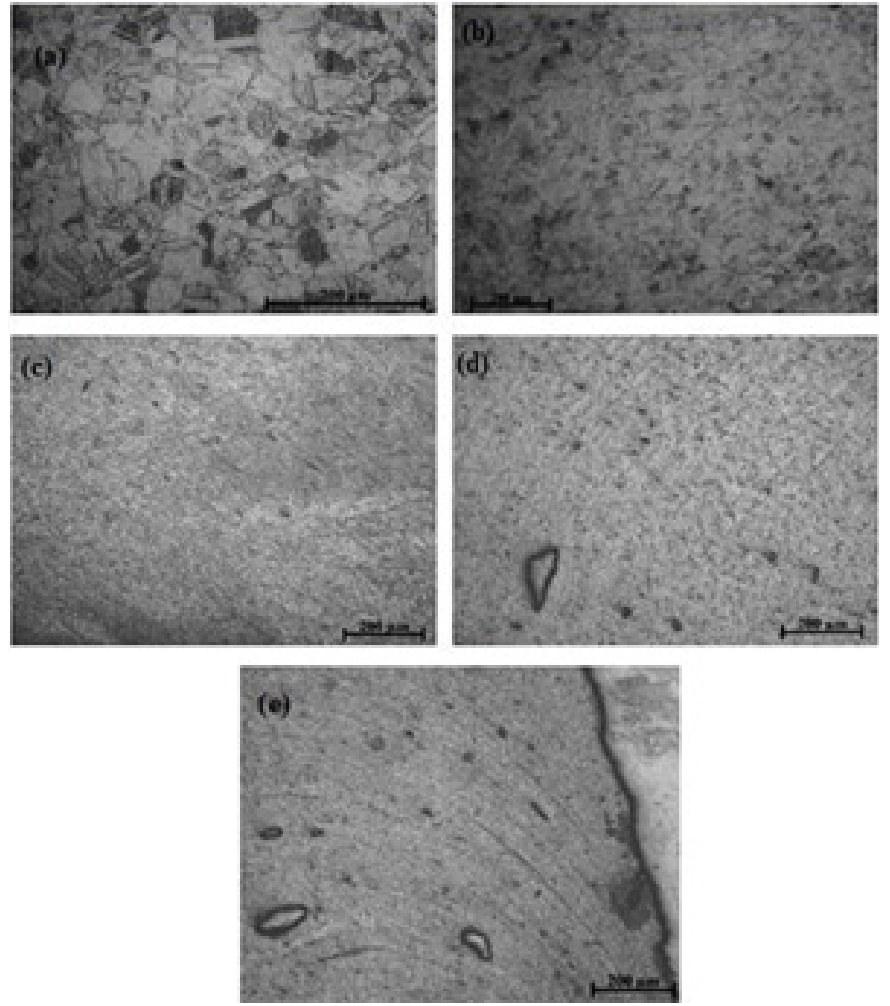

Fig. 1. Optical microstructure of friction stir welded joint at (a) HAZ of steel side (b) SZ of steel side (c) TMAZ of aluminium side (d) SZ of aluminium side (e) interfacial region

Fig. $2 \mathrm{~b}$ shows that the coarse stainless steel particles are directed towards the aluminium side due to the stirring action of the pin which broke the steel particle in bits and attempts to deposit on the aluminium side. Fig. 2(c) shows that at higher tool rotational speed the intermetallics are formed due to the severe plastic deformation and good mixing of material.

The intermetallic phases formed at the interfacial region shown in Fig. 3 consists of $\mathrm{Al}(\sim 66 \mathrm{wt} \%), \mathrm{Fe}(\sim 24 \mathrm{Wt} \%), \mathrm{Ni}$ $(\sim 2.43 \mathrm{wt} \%)$ and $\mathrm{Cr}(\sim 3.50 \mathrm{wt} \%)$. This compositon shows the formation of $\mathrm{Al}_{3} \mathrm{Fe}$ intermetallic compound, which is Al-rich. The intermetallics are formed due to the high tool rotational speed which contribute severe stirring action and more mixing of material that leads to severe plastic deformation followed by dynamic recrystallization. The compostion of the intermetallic phases were found through the Fe-Al, Al-Cr binary phase diagram [13]. The phases have major quantity of $\mathrm{Al}$ and less quantity of $\mathrm{Fe}, \mathrm{Cr}$, Ni. This shows the less influence of chromium and nickel in the formation of phases. 


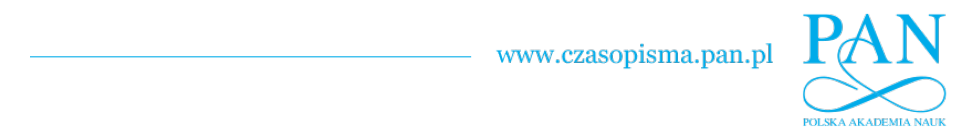

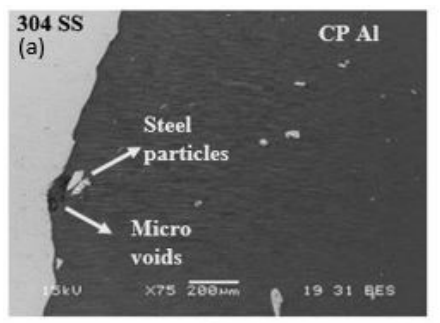
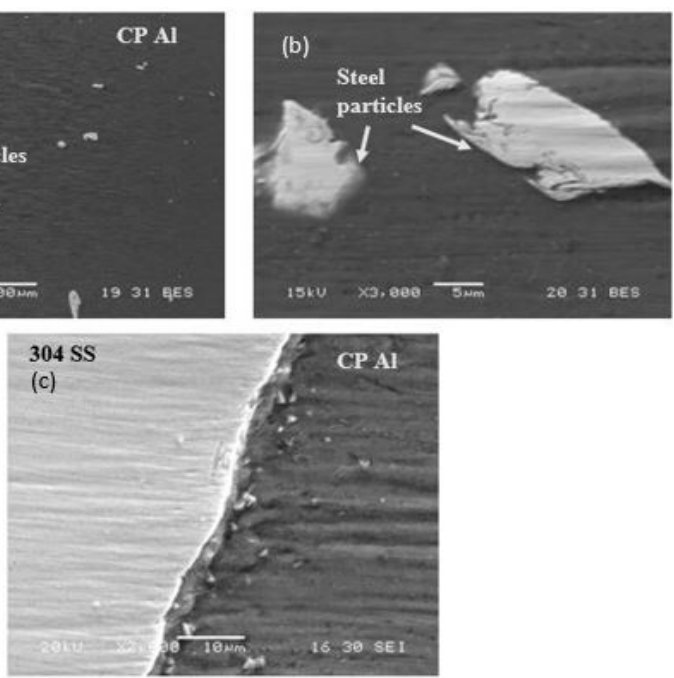

Fig. 2. SEM-BSE images of welded joint at (a) interfacial region (b) steel particle on aluminium side (b) intermetallics formed on interfacial region
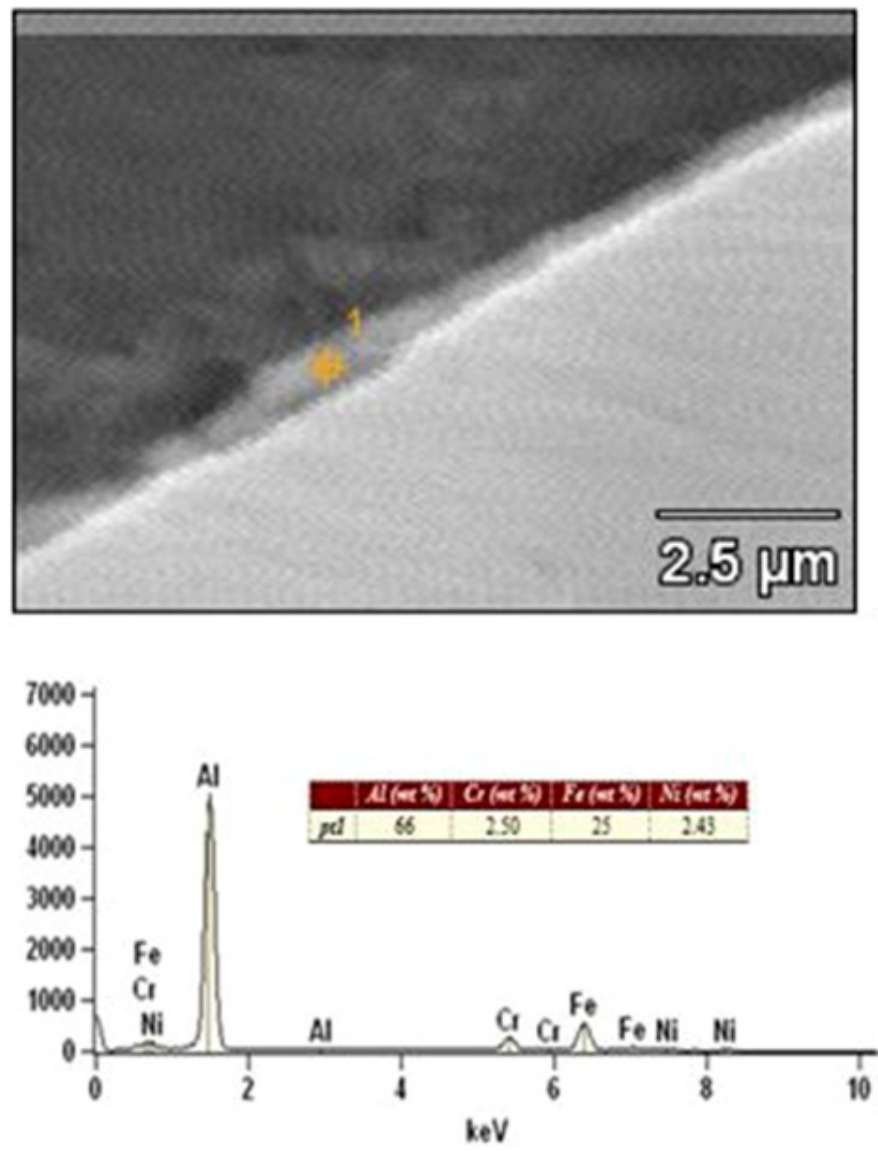

Fig. 3. Energy dispersive spectroscopy images of Interface region

Scanning electron microscopy-EDS mapping at the interface of the welded joint shown in Fig. 4. It confirms that the particles like ferrous, chromium, nickel are present at the interface region and the figure also shows that some particles of $\mathrm{Fe}$ were distributed in the aluminium side. However $\mathrm{Al}$ elements are very minimal in the steel side. Mapping shows that nickel and chromium particle have limited solubility with aluminium.
It shows that the diffusion of $\mathrm{Fe}, \mathrm{Cr}$ and $\mathrm{Ni}$ is significant within $\mathrm{Al}$; however, diffusion of $\mathrm{Al}$ within 304SS is limited.

The intermetallic phases of welded sample at tool rotational speed of $1000 \mathrm{rpm}$ and travel speed of $60 \mathrm{~mm} / \mathrm{min}$ were analysed by X Ray Diffraction patterns which is shown in Fig. 5.The intermetallic compounds formed are $\mathrm{Al}_{13} \mathrm{Fe}_{4}, \mathrm{Al}_{5} \mathrm{Fe}_{2}, \mathrm{FeAl}_{3}$ and $\mathrm{FeAl}_{2}$. Ghosh et al reported that the intermetallics formed while joining $\mathrm{Al} 6061$ and 304 ss are $\mathrm{FeAl}_{2}, \mathrm{Fe}_{2} \mathrm{Al}_{5}$, and $\mathrm{Fe}_{4} \mathrm{Al}_{13}$. Yilmaz reported that the formation of $\mathrm{FeAl}_{3}$ intermetallics while joining of $\mathrm{Al}$ and IF steel.
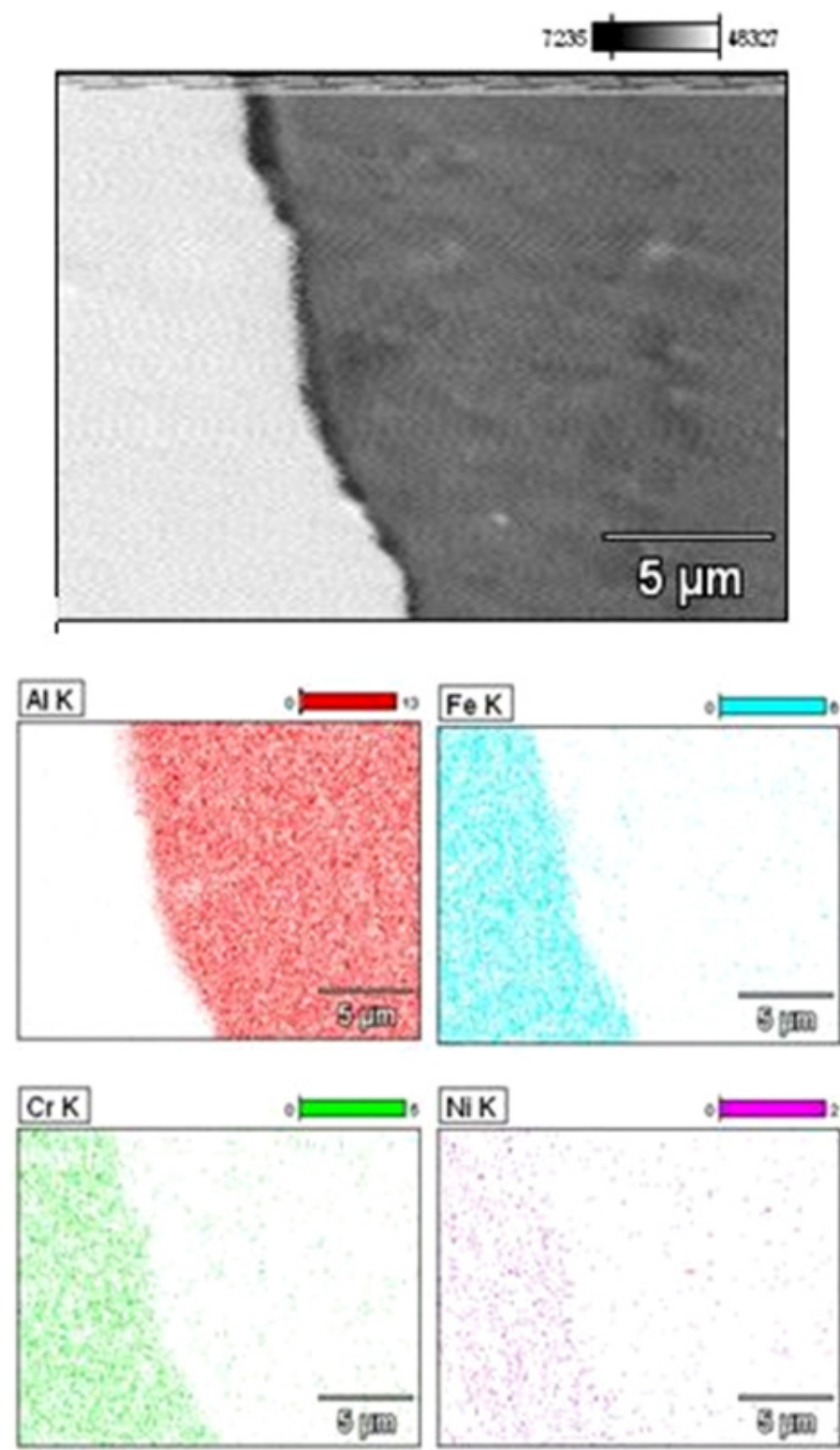

Fig. 4. Scanning electron microscopy-EDS mapping at interface

\subsection{Mechanical properties}

The tensile sample is shown in Fig. 6a and broken tensile sample was shown in Fig. $6 \mathrm{~b}$ the ultimate tensile strength was $78 \%$ of commercially pure aluminium tensile strength. The formation of brittle intermetallics leads to the decrease in the tensile strength. At higher tool rotational speed more deformation 


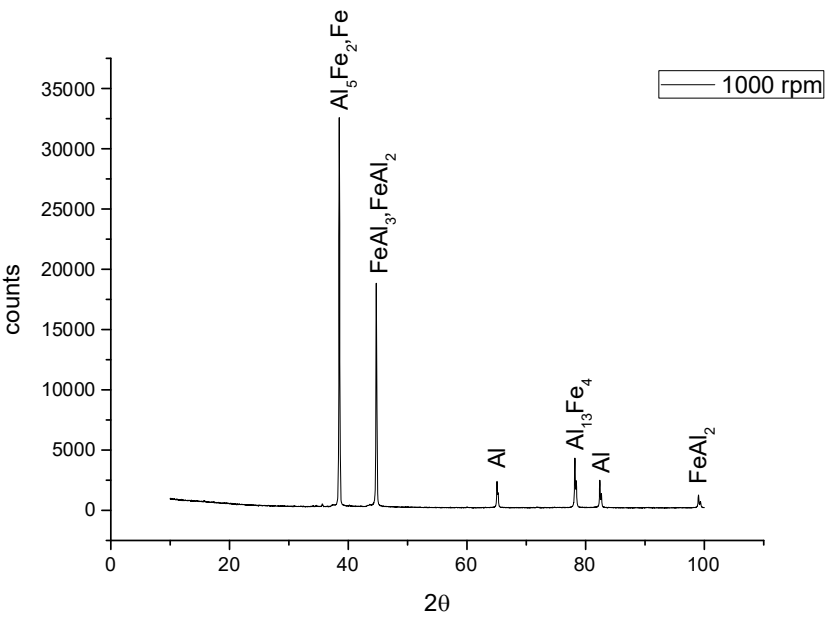

Fig. 5. XRD spectrum of welded sample by tool rotational speed of $1000 \mathrm{rpm}$ and travel speed of $60 \mathrm{~mm} / \mathrm{min}$

and high mixing of materials occurs which leads to formation of brittle intermetallic compounds. The intermetallic compound layer thickness was $4.80 \mu \mathrm{m}$. Yilmaz [11] reported that the tensile strength was highly influenced by the intermetallic compound layer thickness in the reaction zone. Increase in layer thickness leads to weaken the tensile strength.
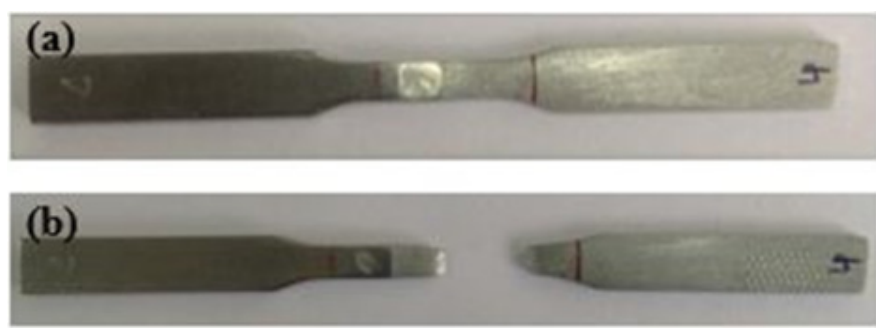

Fig. 6. Tensile sample of welded joint before and after breaking

The fracture surface was observed in Scanning electron microscope using secondary electron mode. The fracture surface of the welded sample of aluminium side is shown in Fig. 7. The dimples are observed at the centre of the sample that shows the ductile fracture which describes the good elongation at the centre of the joint moreover the flat surface observed in the corner which indicate the brittle fracture which explains the cracks are propagated on that area of the welded surface. In Fig. 8 the dimples are observed in the centre of the sample that shows the ductile fracture and the flat surface observed at the corner which reveals the brittle fracture of the welded sample.

The hardness value for the welded sample is shown in Fig. 9. The hardness profile is taken at the centre of the sample. The hardness value reaches maximum at the stir zone due to the mixing of the materials. Moreover which is responsible for the formation of brittle intermetallic compounds. Bozzi et al reported the hardness of the different Intermetallic compounds were FeAl (400 HV), $\mathrm{FeAl}_{3}(820 \mathrm{HV}), \mathrm{FeAl}_{2}(1000 \mathrm{HV})$ and $\mathrm{Fe}_{2} \mathrm{Al}_{5}(1100 \mathrm{HV})$ [12]. The minimum hardness value is in $\mathrm{HAZ}$ region on both the sides.

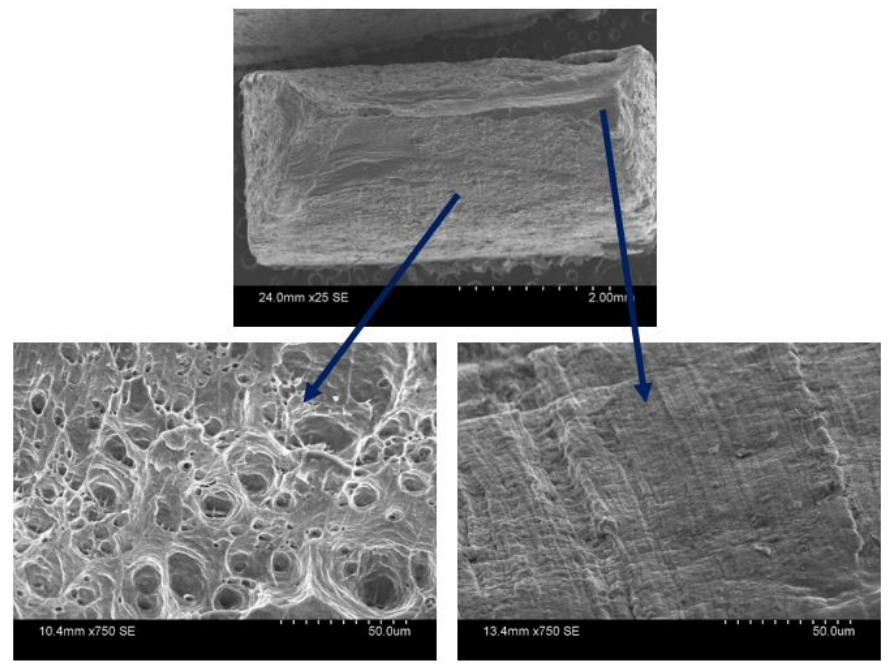

Fig. 7. Fracture surface of aluminium side

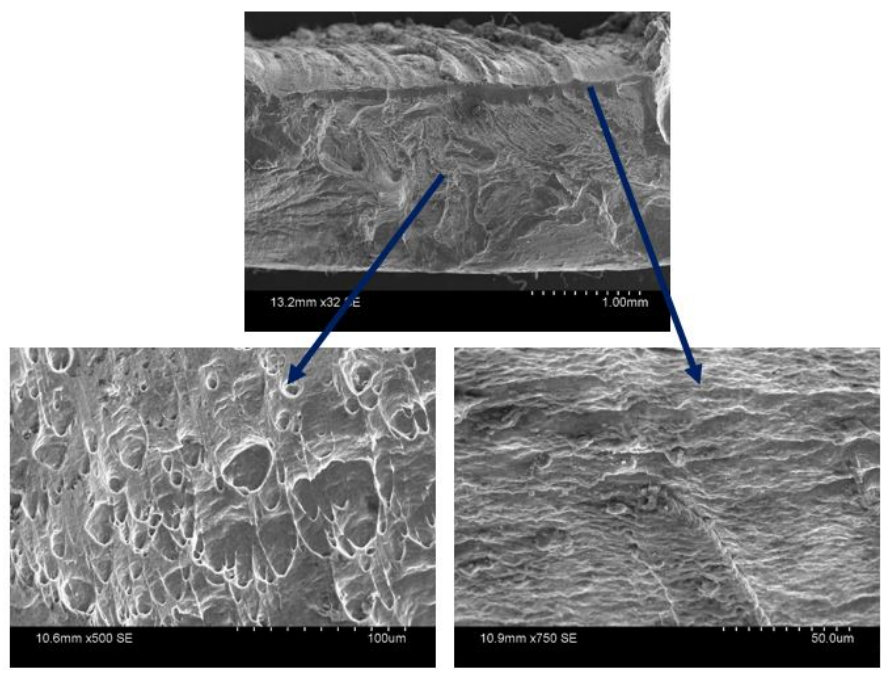

Fig. 8. Fracture surface of stainless steel side

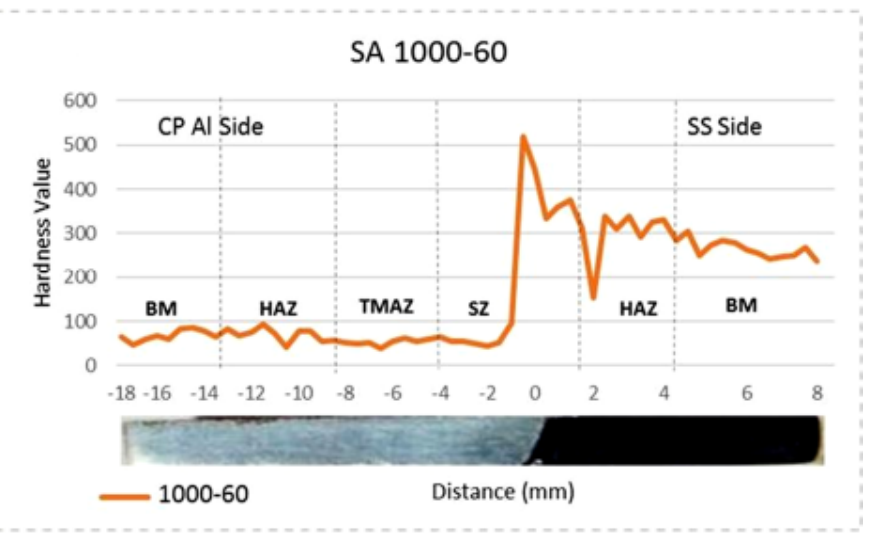

Fig. 9. Hardness value of the welded sample

\section{Conclusions}

Friction stir welding of commercially pure aluminium and 304 stainless steel were performed successfully. The microstructural change in steel side is very minimum due to the difference 
in melting point of the material and the pin is plunged on the aluminium side with an offset of $1.2 \mathrm{~mm}$. SEM with EDS shows the formation of $\mathrm{FeAl}_{3}$ intermetallic compound at the interfacial region. SEM with EDS mapping indicates limited diffusion of aluminium in 304SS side but in CP Al side significant quantity of $\mathrm{Fe}, \mathrm{Cr}$ and $\mathrm{Ni}$ are present. The intermetallic phases found using $\mathrm{X}$ ray Diffraction pattern are $\mathrm{Al}_{13} \mathrm{Fe}_{4}, \mathrm{Al}_{5} \mathrm{Fe}_{2}, \mathrm{FeAl}_{3}$ and $\mathrm{FeAl}_{2}$. The hardness value reaches maximum at the stir zone due to formation of intermetallic compounds.

\section{REFERENCES}

[1] H. Uzun, Mater. Design 26 (1), 41-46 (2005).

[2] V. Satyanarayana, G.M. Reddy, T. Mohandas, J. Mater. Process. Tech. 160 (2), 128-137 (2005.

[3] S. Fukumoto, Scripta Mater. 42 (8), 807-812 (2000).
[4] U.K. Mudali, Energ. Proc. 7, 468-473 (2011).

[5] T. Ogura, Sci. Technol. Weld. Joi. 18 (2), 108-113 (2013).

[6] V. Ryabov, Weld of Aluminium Alloys to Steels. 1998: Harwood Academic.

[7] M.J. Jafarzadegan, Mater. Sci. Tech. 29 (4), 367-372 (2013.

[8] M. Ghosh, R. Gupta, M. Husain, Metallurgical And Materials Transactions A 45 (2), 854-863 (2014).

[9] M. Habibnia, The Int. J. Adv. Manuf. Tech. 76 (5-8), 819-829 (2015).

[10] W.B. Lee, Scripta Mater. 55 (4), 355-358 (2006).

[11] M. Yılmaz, M. Çöl, M. Acet, Mater. Charac. 49 (5), 421-429 (2002).

[12] S. Bozzi, Mater. Sci. Eng. A 527 (16), 4505-4509 (2010).

[13] Metallography structure and phase diagram (2004) in 'ASM Metals Handbook', 8th edition; 2004, Materials Park,OH, ASM International. 